\title{
Optimal Transfer Pricing in a Vertically-related and Imperfectly Competitive Market
}

\author{
Winston W. Chang* \\ Department of Economics, SUNY at Buffalo, Buffalo, NY 14260 \\ Han Eol Ryu \\ Department of Economics, SUNY at Buffalo, Buffalo, NY 14260
}

August 24, 2012

\begin{abstract}
The objective of this paper is to find the significant factors that crucially affect a firm's optimal transfer pricing policy. To achieve such a goal, it suffices to examine three minimalist vertical modelsthe first one contains a vertically integrated monopoly in both input and output markets, the second one consists of a vertically integrated firm that monopolizes an intermediate input for its own and rival's downstream divisions and the third one comprises two vertically integrated firms competing in a final goods market. Four modes of competition are considered - Cournot, Bertrand, Stackelberg quantity and Stackelberg price. The paper shows that the optimal transfer pricing policy depends on four specifications - the vertical structure, the production technology, the demand characteristics and the competition mode. It finds numerous patterns on optimal transfer pricing: for example, under the same demand structure and competition mode, the two vertical models can yield diametrically opposite transfer pricing strategies; within a given vertical model, different competition modes may yield the same or different optimal strategies; and within a given competition mode, the four possible pairings of ordinary substitutes/complements on the demand side and strategic substitutes/complements on the firm side can also produce quite different results. In addition, the paper illustrates how the optimal transfer pricing policy is affected when the additional factors of income tax and tariff distortions are considered. With all the significant factors affecting the optimal transfer pricing delineated, the paper has laid a foundation for further studies in transfer pricing under more general structures. An important implication of our results is that the optimal transfer pricing policy may not be simply determined by the common practice of shifting profits from high- to low-tax jurisdictions.
\end{abstract}

Keywords:Optimal Transfer Price, Vertically Related Market, Imperfect Competition, Intermediate Input, Market Structure.

JEL classification: D43, D49, L13, L22, M21

\footnotetext{
${ }^{*}$ Corresponding author. E-mail: ecowwc@buffalo.edu; Tel: 1-716-645-8671; Fax: 1-716-645-2127. This paper is to be presented at the 20th Annual Conference on Pacific Basin Finance, Economics, Accounting, and Management (PBFEAM) to be held at Rutgers University, USA in September 2012.
} 


\section{Introduction}

Vertical integration enhances production efficiency if the intermediate input market is not competitive. This is because a vertically integrated firm can achieve efficient factor utilization when the transfer prices of the intermediate inputs can be set at their respective marginal costs (see, e.g. Vernon and Graham (1971)). Although the marginal-cost-pricing policy among divisions within a vertically integrated firm is feasible and efficient, it is possible that such a policy does not maximize the firm's total profits if each division is operated separately and the final goods market is imperfectly competitive. In a seminal paper, Hirshleifer (1956) demonstrated this possibility by a numerical example in a model with a vertically integrated firm that monopolizes the intermediate input market and competes against outside downstream firms in a homogeneous final good market. He showed that the optimal transfer price of the intermediate input is higher than its marginal cost but lower than the price charged to the outside firms. Following Hirshleifer, a number of papers have further examined the optimal transfer pricing strategy when a multinational firm has subsidiaries in different countries with different tariff or tax rates 1

There have been some studies which consider multinational firms' optimal transfer pricing policy when strategic effects are present. For example, Schjelderup and Sørgard (1997) considered a model in which a decentralized multinational firm competes with a fully integrated local rival in the Cournot and Bertrand fashion. They showed that if there are no taxes, the optimal transfer price is lower than the upstream division's marginal cost under Cournot competition but is higher under Bertrand competition. But in the presence of taxes, the results depend on the tax structure $\mathrm{I}^{2}$ Zhao (2000) examined a firm's optimal transfer price in the presence of income and repatriation taxes under three different rival firm's organizational structures: it consists of only an upstream division, only a downstream division, and only a fully integrated unit. He showed that among the three rival's structures, the domestic firm adopts the lowest transfer price when the rival firm is fully integrated. Chang and Sugeta (2004) examined a vertically-related but non-integrated model with one upstream and two downstream firms that compete under conjectural variations in the presence of tariff distortions. They examined the upstream firm's discriminating and uniform pricing policies towards the downstreams and also a model of bargaining over the input price ${ }^{3}$

\footnotetext{
${ }^{1}$ See, for example, Horst (1971, 1972), Copithorne (1971), Eden (1978, 1983, 1985), Bond (1980), Diewert (1985), and Hines (1990).

${ }^{2}$ Nielsen et al. (2008) considered a similar model and focused on a multinational firm's optimal choice of centralization vs. decentralization in the presence of tax difference between two countries.

${ }^{3}$ For a comprehensive recent survey on transfer pricing, see Göx and Schiller (2006) and the extensive literature cited therein.
} 
The literature on transfer pricing has mainly focused on the internal divisional pricing strategy when there are distortions of trade and income taxes on divisions located in different tax jurisdictions. Perhaps chiefly with that in focus, most models examined are rather simple in demand or technology specifications. This paper focuses on finding some fundamental factors that crucially affect a firm's optimal transfer pricing policy under general demand and technology structure. To achieve such a goal, we choose to examine three minimalist vertically integrated models without considering trade, income and other tax distortions. The first model briefly reviews a vertically integrated monopoly in both input and output markets. It examines the inherent problem of which unit is to decide the transfer price and establishes the condition for the classic marginal-cost pricing rule for later comparison. The second model builds on a vertically integrated intermediate input monopoly competing against a foreign downstream firm. It serves to reveal how the optimal transfer pricing policy depends on a firm's upstream monopoly power in affecting the downstream competition. The third model explores competition between two vertically integrated firms. This parallel vertical competition model provides a sharp contrast to the second model and produces an array of quite different optimal transfer pricing policy. We allow the final goods to be differentiated, the technologies to be general, and the downstreams to use different intermediate inputs.

We will show that a firm's optimal transfer pricing strategy depends crucially on the basic factors such as the vertical structure, production technology, product characteristics on the demand side and various competition modes between firms. For example, under the same demand characteristics and the competition mode, different models can yield diametrically opposite transfer pricing strategies. Even within a given model, different competition modes can yield the same or different policies. Moreover, within a given competition mode, the various pairings of ordinary substitutes/complements on the demand side and strategic substitutes/complements on the firm side can also have quite different implications for optimal transfer pricing. Specific results will be summarized in various propositions. In addition, we will illustrate the optimal transfer pricing policy when income tax and tariff distortions are introduced into the models.

As a starting point, Section 2 analyzes the basic model of a vertically integrated monopoly in the input and output markets. It considers four transfer price setting types: centralized, upstream monopoly, downstream monopsony, and bargaining between the upstream and downstream divisions. Section 3 examines a duopoly model with a vertically integrated firm competing against a foreign final good producer. Four types of competition modes are analyzed: Cournot, Bertrand, and Stackelberg quantity and price competition. 
Section 4 examines two vertically integrated duopoly model. Section 5 illustrates how the additional factors of income and trade taxes affect the optimal transfer pricing. Finally, some concluding remarks are provided in Section 6 .

\section{A Vertically Integrated Monopoly in an Intermediate Input and Output}

This section briefly examines how the assignment of decision making power on transfer pricing affects a vertically integrated firm. Consider an integrated firm (F1) which consists of two divisions: an upstream (U1) and a downstream (D1). U1 is the only producer of an intermediate input for D1 which is a monopoly in a final good market $4^{4}$

Let the transaction price and quantity of the intermediate input be $v$ and $x$, respectively, and $\mathrm{U} 1$ 's cost function be $c^{u}(x)$ so that its profit function is 5

$$
\pi^{u}=v x-c^{u}(x)=\pi^{u}(x, v),
$$

where $c_{x}^{u}(x)>0$ and $c_{x x}^{u}(x) \geq 0$. For simplicity, assume D1 uses only $x$ as its variable input so that its production function is $q=f(x)$. Let the inverse demand function of D1's final output be $p(q)$ and its cost function be $c^{d}(v, x)=v x+z$ where $z$ is the fixed costs and other factor costs that are taken as given. Without loss of generality, let $z=0$. D1's profit function is

$$
\pi^{d}=p(q) q-c^{d}(v, x)=p(f(x)) f(x)-c^{d}(v, x)=\pi^{d}(x, v)
$$

In this model, there are three decision units: F1, U1 and D1. Unlike U1 and D1 whose interests represent divisional interests, F1's interest lies in the whole firm. This simple setup has a few scenarios, depending on which unit is empowered to do the decision making on transfer pricing. In the absence of an external market, if each division has its own power in buying and selling the intermediate input, the classic bilateral monopoly problem emerges.

\footnotetext{
${ }^{4}$ For ease of presentation, we assume no income and trade tax distortions in the following three sections. The distortions will be briefly discussed in Section 5 .

${ }^{5}$ Throughout this paper, a subscript denotes a partial derivative. To economize notation, we shall use the same function notation but with different arguments when needed.
} 


\subsection{Case 1: F1 Centralizes the Decision}

Since this is a vertically integrated monopoly, F1 can make all the decisions about pricing and output to maximize the whole firm's profits:

$$
\pi=\pi^{u}(x, v)+\pi^{d}(x, v)=p(f(x)) f(x)-c^{u}(x) .
$$

The optimum solution occurs at solving

$$
M R_{F}=M C_{F}
$$

where $M R_{F}=\left[p(f(x))+f(x) p^{\prime}(f(x))\right] f^{\prime}(x)$ is the marginal factor revenue of $x$ which is $x$ 's value marginal product to $\mathrm{D} 1$ and $M C_{F}$ is the marginal factor cost of producing $x$ which is $c_{x}^{u}(x)$. It is clear that $v$ does not matter as far as maximization of $\pi$ is concerned in determining the joint efficient level of output, $x^{e}$. This efficient output corresponds to the case in which there are price taking competitive firms in both the upstream and downstream markets. If there is a need for official reporting on the transfer price, then (3) confirms that F1 can set $v^{e}=c_{x}^{u}\left(x^{e}\right)$ as the transfer price and dictates it to both divisions to comply. This is essentially the result obtained by Hirshleifer (1956).

Proposition 1 The efficient transfer price that maximizes the whole firm's profits is the one that equates marginal factor revenue $\left(M R_{F}\right)$ of the intermediate input and its marginal production cost $\left(M C_{F}\right)$.

In reality, however, it may not be feasible for F1 to make the centralized decision. Consider below other scenarios that $v$ and $x$ are to be settled between $\mathrm{U} 1$ and $\mathrm{D} 1$.

\subsection{Case 2: U1 Is a Monopoly}

In this case $\mathrm{U} 1$ has the monopoly power in selling $x$. Here we assume that though $\mathrm{U} 1$ is a monopoly setting the price for D1, it has to allow D1 to maximize profits by choosing its optimal demand. This in effect is allowing U1 to be the Stackelberg leader and D1 the follower in selling and buying the intermediate input. Thus, U1 sets $v$ subject to D1's derived demand. Under this scenario, D1 is still a profit maximizer on its final good market. 
Let $v^{u}$ be the price charged by U1. D1's derived demand for $x$ is

$$
x^{d}\left(v^{u}\right)=\arg \max _{x} \pi^{d}=p(f(x)) f(x)-v^{u} x,
$$

with the first-order condition $M R_{F}=v^{u}$. Let $v^{u}\left(x^{d}\right)$ be D1's inverse derived demand function. U1 chooses $x^{d}$ to maximize its profit $\pi^{u}=v^{u}\left(x^{d}\right) x^{d}-c^{u}\left(x^{d}\right)$, subject to $v^{u}\left(x^{d}\right)$. The first-order condition is

$$
M M R_{F}=M C_{F}
$$

where $M M R_{F}=v^{u}(x)+x v_{x}^{u}(x)$ is the marginal curve of the $M R_{F}$ curve (where $M R_{F}$ curve is $v^{u}(x)$ curve itself). Thus, the equilibrium $x$ chosen by $\mathrm{U} 1$, denoted by $x^{u}\left(=x^{d}\right)$, is determined by the condition in (4), with the resulting selling price of $v^{u}=v^{u}(x)$.

\subsection{Case 3. D1 Is a Monopsony}

In this case, D1 maximizes its profit by choosing the monopsony price from U1's supply curve of $x$. This is equivalent to allowing D1 to be the Stackelberg leader and $\mathrm{U} 1$ the follower. $\mathrm{U} 1$ takes $v^{d}$ as given and maximizes its profit to supply

$$
x^{u}\left(v^{d}\right)=\arg \max _{x} v^{d} x-c^{u}(x)
$$

with the first-order condition $v^{d}=c_{x}^{u}(x)$. Thus, U1's marginal cost curve $c_{x}^{u}(x)$ becomes its supply curve. D1's choice of $x^{d}$ is

$$
x^{d}=\arg \max _{x} \pi^{d}=p q-v^{d} x=p(f(x)) f(x)-c_{x}^{u}(x) x,
$$

with the first-order condition

$$
M R_{F}=M E_{F}
$$

where $M E_{F}=c_{x}^{u}(x)+x c_{x x}^{u}(x)$ is the marginal factor expenditure which is the marginal curve of U1's supply curve. The above first-order condition determines $x^{d}$, with the resulting $v^{d}=c_{x}^{u}(x)$.

It is easy to see that $v^{d}<v^{e}<v^{u}$ and $x^{e}$ is larger than both $x^{d}$ and $x^{u}$; however, $x^{d}$ can be larger or smaller than $x^{u}$ depending on the cost and demand conditions. 


\subsection{Case 4. Bargaining between U1 and D1}

If neither U1 nor D1 has the sole power to set the price of the intermediate good, they may resort to bargaining. Since there is no external market for the intermediate input, $v$ and $x$ must be bargained to be mutually agreeable to both parties. As before, their profit functions are (1) and (2), respectively. If the bargaining breaks down, both parties earn zero profits. Consider maximization of the Nash function

$$
\max _{x, v} N(x, v)=\max _{x, v}\left(\pi^{u}\right)^{a}\left(\pi^{d}\right)^{(1-a)}
$$

where $a$ and $1-\alpha$ measure the bargaining powers of $\mathrm{U} 1$ and $\mathrm{D} 1$, respectively. The function indicates that their reservation profits are zero. From the first-order conditions $N_{v}(x, v)=0$ and $N_{x}(x, v)=0$, we obtain

$$
\begin{aligned}
a \pi^{d} & =(1-a) \pi^{u}, \\
\pi_{x}^{u}+\pi_{x}^{d} & =0 .
\end{aligned}
$$

The bargaining outcome ensures that joint profits are maximized by choosing $x$, and the negotiated $v$ ensures the sharing of total profits by $(5 \mathrm{a}) .6$ From $(5 \mathrm{~b})$, the negotiated $x$ is equal to the centralized case as implied by (3). In addition, (5a) shows that $a$ and $(1-a)$ are respectively U1's and D1's profit shares. In the extreme case in which $a=1$ or $a=0$, the model effectively reduces to Case 2 or 3 above.

\section{A Vertically Integrated Intermediate Input Monopoly Competing against a Foreign Downstream Firm}

Consider the model in which there are two firms: F1 as described in the previous section and an F2 having only a downstream division (D2) which relies solely on U1's intermediate input to produce its final output $Q .7$ Let the price of the intermediate input paid by $\mathrm{D} 2$ to $\mathrm{U} 1$ be $w$. In the present triangular relationships among U1, D1 and D2, coupled with F1 while F2 is regarded as D2 itself, we cannot allow each unit to have its independent power aiming at its own objective. Here we choose to suppress U1 and allow F1 to make decisions on $v$ and $w$. Therefore, $\mathrm{U} 1$ will merely supply $x$ and $X$ demanded by D1 and D2 at the prices $v$

\footnotetext{
${ }^{6}$ Blair et al. (1989) obtained similar results without explicitly applying a Nash function.

${ }^{7}$ In what follows, when we use the name for Firm 1 (F1) or Firm 2 (F2), we mean the headquarter of the firm whose interest is maximizing the whole firm's profits.
} 
and $w$.

Four modes of competition in the final goods market are analyzed here: Cournot, Bertrand, and Stackelberg leader-follower in quantity and price ${ }^{8}$

\subsection{Cournot Competition}

Let D2's production function be $Q=F(X)$ where $X$ is the amount of intermediate input purchased. Assume $F_{X}(X)>0$ and $F_{X X}(X)<0$. Similarly, for F1, $f_{x}(x)>0$ and $f_{x x}(x)<0$. The two inverse demand functions can now be written as $p=p(q, Q)$ and $P=P(q, Q)$ where $P$ is the price of D2's product. Suppose D1 and D2 are Cournot competitors. At stage 1, F1 chooses $v$ and $w$ so as to maximize its total profits. At stage 2, D1 and D2 choose their outputs to maximize their profits. The game is solved by backward induction.

At stage 2, the two downstreams' profit functions are

$$
\begin{aligned}
\pi^{d} & =p(q, Q) q-v x(q)=\pi^{d}(q, Q, v), \\
\Pi^{d} & =P(q, Q) Q-w X(Q)=\Pi^{d}(q, Q, w),
\end{aligned}
$$

where $x(q)=f^{-1}(q)$ and $X(Q)=F^{-1}(Q)$. To avoid clutter, we use subscripts 1 and 2 for partial derivatives, with $j$ denoting the relevant Fj's variable; for example, $q_{2} \equiv \partial q / \partial P, P_{1} \equiv \partial P / \partial q$, etc. The first-order conditions are simplified as

$$
\begin{gathered}
\pi_{1}^{d}(q, Q, v)=p_{1} q+p-v x_{q}=0, \\
\Pi_{2}^{d}(q, Q, w)=P_{2} Q+P-w X_{Q}=0,
\end{gathered}
$$

which yield their respective reaction functions $q=r(Q, v)$ and $Q=R(q, w)$.

Definition 1 Two goods are strategic substitutes in quantity (SSQ) $\pi_{12}^{d}<0, \Pi_{21}^{d}<0$. They are strategic complements in quantity (SCQ) if $\pi_{12}^{d}>0, \Pi_{21}^{d}>0.9$

\footnotetext{
${ }^{8}$ Note that we have discussed four different modes of competition in this model. Among these, a firm may choose one over the other (see, e.g. Dowrick (1986)). In our paper, the modes of competition are not endogenously chosen but are exogenously assumed.

${ }^{9}$ See Bulow et al. (1985).
} 
From the second-order conditions $\pi_{11}^{d}<0$ and $\Pi_{22}^{d}<0$, it can be verified that both reaction functions are downward (upward) sloping if SSQ (SCQ). Moreover, $r_{v}<0$ and $R_{w}<0$. By solving the two reaction functions, we obtain the Cournot equilibrium outputs as functions of $v$ and $w:^{10} q=q(v, w), Q=Q(v, w)$.

To examine the effects of a change in $v$ and $w$ on the equilibrium outputs, differentiate (7) and solve the resulting equations to obtain

$$
\left(\begin{array}{cc}
q_{v} & q_{w} \\
Q_{v} & Q_{w}
\end{array}\right)=\frac{1}{|H|}\left(\begin{array}{cc}
\Pi_{22}^{d} x_{q} & -\pi_{12}^{d} X_{Q} \\
-\Pi_{21}^{d} x_{q} & \pi_{11}^{d} X_{Q}
\end{array}\right)
$$

where $|H|=\left|\begin{array}{cc}\pi_{11}^{d} & \pi_{12}^{d} \\ \Pi_{21}^{d} & \Pi_{22}^{d}\end{array}\right|>0$ by the stability condition which is commonly assumed ${ }^{11}$ Moreover, it can be shown that the difference in slopes, $1 / r_{Q}-R_{q}=-|H| /\left(\pi_{12}^{d} \Pi_{22}^{d}\right)$. Thus, under SSQ, both reaction curves are negatively sloped and $r$ is steeper than $R$ when looking at the $(q, Q)$ space; but under SCQ, both are positively sloped and $r$ is also steeper than $R$. From (8), some well-known results follow:

Lemma 1 An increase in the price of an intermediate input reduces its own output and increases (decreases) the rival's output if the two goods are $S S Q$ (SCQ).

The equilibrium $\pi^{d}$ and $\pi^{u}$ can now be expressed as

$$
\begin{aligned}
\hat{\pi}^{d}(q, Q, v) & =p(q, Q) q-v x(q), \\
\pi^{d}(v, w) & =\pi^{d}(q(v, w), Q(v, w), v), \\
\hat{\pi}^{u}(q, Q, v, w) & =v x(q)+w X(Q)-c^{u}(x(q), X(Q)), \\
\pi^{u}(v, w) & =\hat{\pi}^{u}(q(v, w), Q(v, w), v, w) .
\end{aligned}
$$

\footnotetext{
${ }^{10}$ To be precise, the $q$ in the next equation, for example, should be differentiated with a new symbol such as $q^{*}$ since it is the Cournot-Nash equilibrium output. But to avoid clutter, we will continue using $q$ whenever it is clear from the context or from the arguments provided.

${ }^{11}$ Though there is no dynamic system here, one can argue that if adding the assumption that a firm will increase its output whenever its marginal profit is positive, then the stability conditions require $\pi_{11}^{d}+\Pi_{22}<0$ and $|H|>0$.
} 
At stage 1, F1 chooses $v$ and $w$ to maximize its total profits $\pi(v, w)=\pi^{u}(v, w)+\pi^{d}(v, w)$. The first-order conditions are

$$
\begin{aligned}
& \pi_{v}(v, w)=\pi_{v}^{u}+\pi_{v}^{d}=0 . \\
& \pi_{w}(v, w)=\pi_{w}^{u}+\pi_{w}^{d}=0
\end{aligned}
$$

where, by (7),

$$
\begin{aligned}
& \pi_{v}^{u}(v, w)=\hat{\pi}_{1}^{u} q_{v}+\hat{\pi}_{2}^{u} Q_{v}+\hat{\pi}_{v}^{u}=\left(v-c_{x}^{u}\right) x_{q} q_{v}+\left(w-c_{X}^{u}\right) X_{Q} Q_{v}+x, \\
& \pi_{v}^{d}(v, w)=\hat{\pi}_{1}^{d} q_{v}+\hat{\pi}_{2}^{d} Q_{v}+\hat{\pi}_{v}^{d}=\hat{\pi}_{Q}^{d} Q_{v}+\hat{\pi}_{v}^{d}=q p_{2} Q_{v}-x \\
& \pi_{w}^{u}(v, w)=\hat{\pi}_{1}^{u} q_{w}+\hat{\pi}_{2}^{u} Q_{w}+\hat{\pi}_{w}^{u}=\left(v-c_{x}^{u}\right) x_{q} q_{w}+\left(w-c_{X}^{u}\right) X_{Q} Q_{w}+X \\
& \pi_{w}^{d}(v, w)=\hat{\pi}_{1}^{d} q_{w}+\hat{\pi}_{2}^{d} Q_{w}=\hat{\pi}_{Q}^{d} Q_{w}=q p_{2} Q_{w} .
\end{aligned}
$$

Thus, (10) becomes

$$
\begin{aligned}
& \left(v-c_{x}^{u}\right) x_{q} q_{v}+\left(w-c_{X}^{u}\right) X_{Q} Q_{v}=-q p_{2} Q_{v} \\
& \left(v-c_{x}^{u}\right) x_{q} q_{w}+\left(w-c_{X}^{u}\right) X_{Q} Q_{w}=-q p_{2} Q_{w}-X
\end{aligned}
$$

Solve (11) to obtain

$$
\begin{aligned}
v-c_{x}^{u} & =\frac{Q_{v} X}{x_{q}|J|} \\
w-c_{X}^{u} & =-\frac{q p_{2}}{X_{Q}}-\frac{q_{v} X}{X_{Q}|J|},
\end{aligned}
$$

where $|J| \equiv\left|\begin{array}{cc}q_{v} & q_{w} \\ Q_{v} & Q_{w}\end{array}\right|$. Clearly, $|H|>0$ implies $|J|>0$. Thus, $v-c_{x}^{u}$ has the sign of $Q_{v}$ and $Q_{v}$ has the opposite sign of $\Pi_{21}^{d}$ as is seen from (8). It is seen that in general the optimal transfer price is not the marginal cost.

Next, consider $w-c_{X}^{u}$. The two goods are ordinary substitutes in quantity (OSQ) if $p_{2}<0$ and $P_{1}<0$, and are ordinary complements in quantity (OCQ) if $p_{2}>0$ and $P_{1}>0$. In general, there are no mutual 
implications between ordinary and strategic substitutes/complements. Note that the term $\pi_{12}^{d}$ is

$$
\pi_{12}^{d}=q p_{12}+p_{2}
$$

Thus strategic substitutes can coexist with OSQ or OCQ. This applies to D2 by symmetry. A sufficiently large ordinary effect will likely result in having the two terms $p_{2}$ and $\pi_{12}^{d}$ to have the same sign. They will be equal in value only if the demand functions are linear. From (12b), we infer that $w-c_{X}^{u}$ is positive under OSQ; however, under OCQ, the sign of $w-c_{X}^{u}$ is ambiguous 12

Let $m\left(=v-c_{x}^{u}\right)$ and $m^{*}\left(=w-c_{X}^{u}\right)$ be the margins of the intermediate inputs applied to D1 and D2, respectively. From (12), if D1 and D2 have the same technology, then $x_{q}=X_{Q}$, and we obtain

$$
m-m^{*}=\frac{1}{x_{q}}\left(\frac{q_{v}+Q_{v}}{|J|}+q p_{2}\right)
$$

Using (8), we have

$$
q_{v}+Q_{v}=\frac{x_{q}}{|H|}\left(\Pi_{22}^{d}-\Pi_{21}^{d}\right)
$$

If we assume the dominant own output effect on own marginal profit, $\left|\Pi_{22}^{d}\right|>\left|\Pi_{21}^{d}\right|$, then $q_{v}+Q_{v}<0$. This, together with OSQ implies $m<m^{*}$ and we obtain: ${ }^{13}$

Proposition 2 Suppose a vertically integrated firm is a monopoly in the intermediate input market and a Cournot-Nash competitor against a rival downstream firm in the final goods market.

(i) If the two final goods are strategic substitutes (complements), then the optimal internal transfer price is higher (lower) than the marginal cost.

(ii) If the two goods are ordinary substitutes, then the selling price of the intermediate input to the rival firm is always higher than its marginal cost; however, if they are very strong ordinary complements, then the opposite result may occur: 14

(iii) Assume the two goods are ordinary substitutes. If either the two goods are strategic complements or

\footnotetext{
${ }^{12}$ If the two goods are very close substitutes and if D1 and D2 have very similar technologies, then there is a distinct possibility that U1 will foreclose D2. We disregard this possibility here. Zhao (2000) examined the case of homogeneous good in detail and showed the condition that leads to foreclosure in the presence of tax distortions. His result implies that when there are no tax distortions, foreclosure ensues.

${ }^{13}$ If the two final goods are independent, then the marginal-cost transfer pricing rule always holds. This result applies to the whole paper, since in this case, the model essentially reduces to Case 1 of the integrated monopoly model.

${ }^{14}$ If the two goods are sufficiently strong ordinary complements, then by $[13), \pi_{12}^{d}>0$; therefore, from $(8), Q_{v}<0$ and thus $v<c_{x}^{u}$.
} 
there exists a dominant rival's output effect on rival's own marginal profit, then the margin charged to the rival's downstream is higher than that charged to own downstream.

In the present model, $\mathrm{F} 1$ has two instruments $v$ and $w$ to use and two profit sources $\pi^{u}$ and $\pi^{d}$ to consider. The above proposition shows that it places emphasis on the $\pi^{u}$ source by selling at positive margins to D1 and D2 in the presence of some sort of substitutability. It tends to discriminate against D2 in favor of D1 when the two goods are OSQ. However, F1 switches its emphasis to promoting the downstream market by selling $x$ and $X$ below their marginal costs in the presence of some sort of complementarity.

Note that the magnitude of the optimal transfer price is affected by the technology factor $x_{q}$, though such factor does not affect the qualitative results shown in the above proposition.

\subsection{Bertrand Competition}

This section considers the case that D1 and D2 are Bertrand competitors. Let the demand functions of the two goods be $q=q(p, P)$ and $Q=Q(p, P)$. At stage $1, \mathrm{~F} 1$ chooses $v$ and $w$, and at stage 2, D1 and D2 engage in price competition. D1 chooses $p$ to maximize

$$
\pi^{d}=p q(p, P)-v x(q(p, P))=\hat{\pi}^{d}(p, P, v)
$$

given $v$ and $w$, implying the first-order condition

$$
\pi_{1}^{d}(p, P, v)=q+p q_{1}-v x_{q} q_{1}=0
$$

which yields its reaction function $p=r(P, v)$. Similarly, D2 's first-order condition is

$$
\Pi_{2}^{d}(p, P, w)=Q+P Q_{2}-w X_{Q} Q_{2}=0
$$

which yields its reaction function $P=R(p, w)$. The two reaction functions can be solved to obtain the equilibrium $p$ and $P$ as functions of $v$ and $w: p=p(v, w)$ and $P=P(v, w)$. The resulting equilibrium $\pi^{d}$ can be expressed as $\pi^{d}(v, w)=\hat{\pi}^{d}(p(v, w), P(v, w), v)$. 
By the same method as in the Cournot case, we obtain

$$
\left(\begin{array}{cc}
p_{v} & p_{w} \\
P_{v} & P_{w}
\end{array}\right)=\frac{1}{\left|H_{1}\right|}\left(\begin{array}{cc}
\Pi_{22}^{d} x_{q} q_{1} & -\pi_{12}^{d} X_{Q} Q_{2} \\
-\Pi_{21}^{d} x_{q} q_{1} & \pi_{11}^{d} X_{Q} Q_{2}
\end{array}\right)
$$

where $\left|H_{1}\right|=\left|\begin{array}{cc}\pi_{11}^{d} & \pi_{12}^{d} \\ \Pi_{21}^{d} & \Pi_{22}^{d}\end{array}\right|>0$ by the stability condition.

Definition 2 Two goods are strategic substitutes in price (SSP) if $\pi_{12}^{d}<0, \Pi_{21}^{d}<0$. They are strategic complements in price (SSP) if $\pi_{12}^{d}>0, \Pi_{21}^{d}>0$.

Using the stability and the second-order conditions for profit maximization, together with the usual downward-sloping demand functions $q_{1}<0$ and $Q_{2}<0$, we infer from (19) that $p_{v}>0, P_{w}>0$, sign $p_{w}=\operatorname{sign} \pi_{12}^{d}$ and $\operatorname{sign} P_{v}=\operatorname{sign} \Pi_{21}^{d}$.

U1's profit function can now be written as

$$
\begin{aligned}
\hat{\pi}^{u}(p, P, v, w) & =v x(q(p, P))+w X(Q(p, P))-c^{u}(x(q(p, P)), X(Q(p, P))), \\
\pi^{u}(v, w) & =\pi^{u}(p(v, w), P(v, w), v, w) .
\end{aligned}
$$

At stage $1, \mathrm{~F} 1$ chooses $v$ and $w$ to maximize its total profits

$$
\pi(v, w)=\pi^{u}(v, w)+\pi^{d}(v, w) .
$$

In Appendix 7.1, we derive the following two optimal markups:

$$
\begin{aligned}
v-c_{x}^{u} & =\frac{X Q_{v}^{*}+Q_{1} q_{2}\left|J_{1}\right|\left(p-v x_{q}\right)}{x_{q}\left(Q_{2} q_{1}-Q_{1} q_{2}\right)\left|J_{1}\right|}, \\
w-c_{X}^{u} & =-\frac{X q_{v}^{*}+q_{2} q_{1}\left|J_{1}\right|\left(p-v x_{q}\right)}{X_{Q}\left(Q_{2} q_{1}-Q_{1} q_{2}\right)\left|J_{1}\right|} .
\end{aligned}
$$

where $Q_{v}^{*}=Q_{2} P_{v}+Q_{1} p_{v}, q_{v}^{*}=q_{2} P_{v}+q_{1} p_{v}$ and $\left|J_{1}\right| \equiv\left|\begin{array}{cc}p_{v} & p_{w} \\ P_{v} & P_{w}\end{array}\right| . Q_{v}^{*}$ and $q_{v}^{*}$ are the total effects of a change in $v$ on the equilibrium $Q$ and $q$, respectively. From $(19)$, it is immediate that sign $\left|J_{1}\right|=\operatorname{sign}$ $\left|H_{1}\right|>0$. 
The counterpart of (13) in the Bertrand case is

$$
\pi_{12}^{d}=\left(p-v x_{q}\right) q_{12}+\left(1-v q_{1} x_{q q}\right) q_{2} .
$$

Again strategic substitutes in price can coexist with ordinary substitutes or complements in price. Notice first that $1-v q_{1} x_{q q}>1$ since $x_{q q}>0$ by the assumption $f_{x x}(x)<0$. Since $p-v x_{q}>0$ by the first-order condition (17), the two terms $\pi_{12}^{d}$ and $q_{2}$ will always have the same sign only if the demand functions are linear. In general, a sufficiently large ordinary effect will pool both terms $\pi_{12}^{d}$ and $q_{2}$ to have the same signs. To determine the two markups $v-c_{x}^{u}$ and $w-c_{X}^{u}$, we assume

(A1) Dominant own price effect on output demand: $\left|q_{1}\right|>\left|q_{2}\right|$ and $\left|Q_{2}\right|>\left|Q_{1}\right|$.

It follows that $Q_{2} q_{1}-Q_{1} q_{2}>0$. From (17), we know $p-v x_{q}>0$. In addition, we call the two goods ordinary substitutes in price (OSP) if $q_{2}>0$ and $Q_{1}>0$, and ordinary complements in price (OCP) if $q_{2}<0$ and $Q_{1}<0$. Then under OSP and SSP, $Q_{v}^{*}>0$ and $q_{v}^{*}<0$.

It can be shown that

$$
\begin{aligned}
m-m^{*} & =\frac{X\left(Q_{v}^{*}+q_{v}^{*}\right)+\left(Q_{1}+q_{1}\right) q_{2}\left|J_{1}\right|\left(p-v x_{q}\right)}{x_{q}\left(Q_{2} q_{1}-Q_{1} q_{2}\right)\left|J_{1}\right|} \\
& =\frac{-X q_{1} x_{q}\left[\left(Q_{2}+q_{2}\right) \Pi_{21}^{d}-\left(Q_{1}+q_{1}\right) \Pi_{22}^{d}\right]+\left(p-v x_{q}\right) q_{2}\left(Q_{1}+q_{1}\right)\left|J_{1}\right|\left|H_{1}\right|}{x_{q}\left(Q_{2} q_{1}-Q_{1} q_{2}\right)\left|J_{1}\right|\left|H_{1}\right|},
\end{aligned}
$$

where the second equation follows from (19). As before, it is reasonable to assume that the own input price effect of $v$ on the equilibrium output $q$ through changes in $p$ dominates the indirect effect through $P$ so that $\left|q_{v}^{*}\right|>\left|Q_{v}^{*}\right|$. Thus, under OSP, 24a implies $m<m^{*}$. Alternatively, under (A1), if OSP and SCP, then (24b) also implies $m<m^{*}$. Therefore, we obtain

Proposition 3 Suppose a vertically integrated firm is a monopoly in the intermediate input market and is a Bertrand competitor against a downstream rival in the final goods market. Then:

(i) Under (A1), if the two goods are ordinary and strategic substitutes, the optimal internal transfer price and the selling price of the intermediate input to the rival are both greater than their respective marginal costs.

(ii) If the two goods are ordinary or strategic complements, then the optimal internal transfer price and the selling price of the intermediate input to the rival may be higher or lower than their respective marginal 
costs.

(iii) Assume (A1) holds and that the two goods are ordinary substitutes. If either the own input price effect of $v$ on the equilibrium output $q$ through changes in $p$ dominates the indirect effect through changes in $P$ or if the two goods are strategic complements, then the margin charged to the rival's downstream is higher than that charged to own downstream.

Result (i) that both positive margins are optimal for F1 in the presence of substitutability is similar to the Cournot case. This is again due to the monopoly supplier position of $\mathrm{U} 1$ that allows F1 to exploit D2.

\subsection{Stackelberg Leader-follower Competition}

\subsubsection{Stackelberg Quantity Competition}

Consider the case in which D1 is the Stackelberg quantity leader and D2 the follower. Assume that F1 chooses $v$ and $w$ at stage 1, D1 chooses $q$ at stage 2, and D2 chooses $Q$ at stage 3. By backward induction, $\mathrm{D} 2$ 's problem is the same as maximizing $\Pi^{d}$ in $6 \mathrm{~b}$, yielding its reaction function $Q=R(q, w)$.

At stage 2, D1 chooses $q$ to maximize $\pi^{d}=p(q, Q) q-v x(q)$ subject to $Q=R(q, w)$. Let

$$
\pi^{d}(q, v, w) \equiv p(q, R(q, w)) q-v x(q)
$$

The first-order condition can now be written as

$$
\pi_{q}^{d}=\left(p_{1}+p_{2} R_{q}\right) q+p-v x_{q}=0
$$

which yields the equilibrium $q=q(v, w)$ and $Q(v, w)=R(q(v, w), w)$. From 25) and 9c), the equilibrium $\pi^{d}$ and $\pi^{u}$ can now be expressed as

$$
\begin{aligned}
& \pi^{d}(v, w)=\pi^{d}(q(v, w), v, w) \\
& \pi^{u}(v, w)=\pi^{u}(x(q(v, w)), X(R(q(v, w), w)), v, w) .
\end{aligned}
$$

At stage 1, F1 chooses $v$ and $w$ to maximize its total profits $\pi(v, w)=\pi^{u}(v, w)+\pi^{d}(v, w)$. The 
first-order conditions are

$$
\begin{aligned}
& \pi_{v}(v, w)=\pi_{v}^{u}(v, w)+\pi_{v}^{d}(v, w)=0, \\
& \pi_{w}(v, w)=\pi_{w}^{u}(v, w)+\pi_{w}^{d}(v, w)=0 .
\end{aligned}
$$

where

$$
\begin{gathered}
\pi_{v}^{u}=x+\left(v-c_{x}^{u}\right) x_{q} q_{v}+\left(w-c_{X}^{u}\right) X_{Q} q_{v} R_{q}, \pi_{v}^{d}=-x \\
\pi_{w}^{u}(v, w)=X+\left(v-c_{x}^{u}\right) x_{q} q_{w}+\left(w-c_{X}^{u}\right) X_{Q}\left(q_{w} R_{q}+R_{w}\right), \pi_{w}^{d}=p_{2} R_{w}
\end{gathered}
$$

by direct calculations with the use of (26). Solve (27), we have

$$
\begin{gathered}
v-c_{x}^{u}=\frac{R_{q}}{x_{q} R_{w}}\left(X+q p_{2} R_{w}\right), \\
w-c_{X}^{u}=-\frac{1}{X_{Q} R_{w}}\left(X+q p_{2} R_{w}\right),
\end{gathered}
$$

and

$$
v-c_{x}^{u}=-\frac{R_{q} X_{Q}}{x_{q}}\left(w-c_{X}^{u}\right)
$$

It appears that each markup may be positive or negative. To obtain some determinate results, we need to examine some comparative-statics properties. From (7b) and (26), $q_{v}=-\pi_{1 v} / \pi_{11}=x_{q} / \pi_{11}<0$ and $R_{w}=-\Pi_{2 w}^{d} / \Pi_{22}^{d}=1 / \Pi_{22}^{d}<0$ by the second-order conditions. From $(7), R_{q}=-\Pi_{21}^{d} / \Pi_{22}^{d} \gtreqless 0$ if and only if $\Pi_{21}^{d} \gtreqless 0$. Furthermore, we have

$$
m-m^{*}=\frac{\left(X+q p_{2} R_{w}\right)\left(\Pi_{22}^{d}-\Pi_{21}^{d}\right)}{x_{q} R_{w} \Pi_{22}^{d}} .
$$

By inspection of the sign patterns in the preceding four equations, we obtain

Proposition 4 Suppose a vertically integrated firm is a monopoly in the intermediate input market and a Stackelberg leader in the final goods market in which it competes with its rival. Then:

(i) If the two goods are always ordinary substitutes and if they are strategic substitutes (complements), then the optimal internal transfer price is higher (lower) than the marginal cost. 
(ii) If the two goods are ordinary substitutes, then the selling price of the intermediate input to the rival firm is always higher than the marginal cost irrespective of strategic substitutes or complements.

(iii) The two markups have the same (opposite) signs if the two goods are strategic substitutes (complements).

(iv) Assume the two goods are ordinary substitutes. If either they are strategic complements or there exists a dominant follower's own output effect on its marginal profit, then the margin charged to the follower is higher than that charged to leader's own downstream.

In the present case, D1 has full foresight of D2's strategy. This, coupled with U1's monopoly supplier position, enables $\mathrm{F} 1$ to charge a positive margin to $\mathrm{D} 2$ whenever the two goods are OSQ.

In the case where the two goods are OSQ and SSQ, charging a positive $m^{*}$ instead of a zero or negative $m^{*}$ by F1 will lower $Q$. This will raise $q$ through OSQ and through SSQ. As a result, the double expansion of $q$ enables F1 to raise U1's profit by charging a positive $m$. However, in the case where the two goods are OSQ and SCQ, our finding indicates that the direct revenue effect of charging a positive $m^{*}$ is still called for in the present case. As a result, $Q$ decreases. There are two consequential opposite changes in $q$-it increases through OSQ but decreases through SCQ. The combined effect is ambiguous. Our result nonetheless indicates that F1 should lower $m$ (to raise $q$ so as to raise D1's profit) to the extent of a negative level.

\subsubsection{Stackelberg Price Competition}

Next, we consider the case in which D1 is a price leader and D2 a follower. At stage 1, F1 chooses the two input prices $v$ and $w$ for $\mathrm{D} 1$ and $\mathrm{D} 2$, respectively. At stage 2, D1 chooses $p$, and at stage 3, D2 chooses $P$ to maximize their respective profits.

D2's profit maximization condition is the same as (18) so that its reaction function can be expressed as $P=\tilde{R}(p, w) \cdot 15 \mathrm{D} 1$ 's profit function now becomes $\pi^{d}(p, P, v)=p q(p, P)-v x(q(p, P))$. Maximization of $\pi^{d}$ subject to $P=\tilde{R}(p, w)$ implies

$$
\pi_{1}^{d}(p, \tilde{R}(p, w), v)=\left(q_{1}+q_{2} \tilde{R}_{p}\right) p+q-v x_{q}\left(q_{1}+q_{2} \tilde{R}_{p}\right)=0,
$$

\footnotetext{
${ }^{15}$ Under the Stackelberg price competition, the model structure is more complicated than other cases. To avoid possible confusion, we attach a tilde to the relevant variables or functional notations.
} 
which yields the equilibrium $p=p(v, w), P(v, w)=\tilde{R}(p(v, w), w)$ and $\pi^{d}(v, w)=\pi^{d}(p(v, w), v, w)$. Since $\pi^{u}(x, X, v, w)=v x+w X-c^{u}(x, X)$, we can express $\pi^{u}$ as

$$
\begin{aligned}
\pi^{u}(p, P, v, w) & =\pi^{u}(x(q(p, \tilde{R})), X(Q(p, \tilde{R})), v, w) \\
\pi^{u}(v, w) & =\pi^{u}(p(v, w), \tilde{R}(p(v, w), w), v, w)
\end{aligned}
$$

At stage 1, F1 maximizes its total profits

$$
\pi(v, w)=\pi^{u}(v, w)+\pi^{d}(v, w)
$$

with respect to $v$ and $w$. In Appendix 7.2, we show the following optimal markups:

$$
\begin{gathered}
v-c_{x}^{u}=\frac{\tilde{Q}_{p}^{*}\left[\left(p-v x_{q}\right) q_{2} \tilde{R}_{w}+X\right]}{\left(q_{1} Q_{2}-q_{2} Q_{1}\right) x_{q} \tilde{R}_{w}}, \\
w-c_{X}^{u}=-\frac{\tilde{q}_{p}^{*}\left[\left(p-v x_{q}\right) q_{2} \tilde{R}_{w}+X\right]}{\left(q_{1} Q_{2}-q_{2} Q_{1}\right) X_{Q} \tilde{R}_{w}},
\end{gathered}
$$

where $\tilde{q}_{p}^{*}=q_{1}+q_{2} \tilde{R}_{p}$ and $\tilde{Q}_{p}^{*}=Q_{1}+Q_{2} \tilde{R}_{p}$. Thus,

$$
v-c_{x}^{u}=-\frac{x_{q} \tilde{Q}_{p}^{*}}{X_{Q} \tilde{q}_{p}^{*}}\left(w-c_{X}^{u}\right)
$$

Notice that from $\left[18\right.$, we have $\tilde{R}_{p}=-\Pi_{21}^{d} / \Pi_{22}^{d} \gtreqless 0$ if and only if $\Pi_{21}^{d} \gtreqless 0$, and $\tilde{R}_{w}=-\Pi_{2 w}^{d} / \Pi_{22}^{d}=$ $X_{Q} Q_{2} / \Pi_{22}^{d}$ which is always positive. In addition, from 31 , we have $\pi_{1}^{d}=q+\left(p-v x_{q}\right) \tilde{q}_{p}^{*}=0$. Thus, $\left(p-v x_{q}\right) \tilde{q}_{p}^{*}<0$. It follows that if the two goods are either both OSP and SSP or both OCP and SCP, then $p-v x_{q}>0$ and $\tilde{q}_{p}^{*}<0$.

From 31 , we have $p_{v}=-\pi_{1 v} / \pi_{11}=x_{q} \tilde{q}_{p}^{*} / \pi_{11}$, which has the opposite sign of $\tilde{q}_{p}^{*}$. Also, $\tilde{Q}_{p}^{*}$ is positive if OSP and SSP but is negative if OCP and SCP. By (A1), $q_{1} Q_{2}-q_{2} Q_{1}$ is positive. Finally, we have

$$
m-m^{*}=\frac{\left[\left(Q_{1}+q_{1}\right)+\left(Q_{2}+q_{2}\right) \tilde{R}_{p}\right]\left[\left(p-v x_{q}\right) q_{2} \tilde{R}_{w}+X\right]}{\left(q_{1} Q_{2}-q_{2} Q_{1}\right) x_{q} \tilde{R}_{w}} .
$$

It can be verified that if (A1) and SCP, then $\left(Q_{1}+q_{1}\right)+\left(Q_{2}+q_{2}\right) \tilde{R}_{p}<0$, which, together with OSP, implies $m<m^{*}$. Therefore, from the preceding four equations, we obtain 
Proposition 5 Suppose a vertically integrated firm is a monopoly in the intermediate input market and is a price leader in the final goods market. Then:

(i) Under (A1), if the two goods are ordinary and strategic substitutes, then the optimal internal transfer price and the selling price of the intermediate input to the rival firm are both higher than their respective marginal costs.

(ii) If the two goods are both ordinary and strategic substitutes, then the two markups always have the same sign, but if they are both ordinary and strategic complements, the opposite result occurs.

(iii) Under (A1), if the two goods are ordinary substitutes and strategic complements, then the margin charged to the rival is higher than that charged to own downstream.

In the present price leader case, the preceding result (i) is similar to the quantity leader case. Because of D1's leadership position, the downstream market is effectively controlled by D1. Therefore, F1's primary goal then is to charge a positive margin $w$ on $\mathrm{D} 2$ to raise U1's profit. As a result, $P$ will increase. This will generate a double reduction in $p$ through ordinary and strategic substitutes. To reduce the harmful price reduction effect, F1 must lean towards raising $v$. Our result indicates that $v$ should be raised to a positive level.

There is an interesting difference between the price and the quantity leader case. When the two goods are OSP and SCP, the quantity case calls for a negative $v$ but here we do not obtain such a definitive result, though we still find that F1 will charge a higher margin to D2 than to D1.

\section{Competition between Two Vertically Integrated Firms}

In this section, we consider the case in which there are two vertically integrated firms, F1 and F2, each producing its own intermediate input for its final good. The structure of F1 is as described before and now F2 consists of $\mathrm{U} 2$ and D2. U1's cost function is now changed to $c^{u}(x)$ and $\mathrm{U} 2$ 's is $C^{u}(X)$. Let the counterpart of $v$ for F2 be $V$. Thus, U1's profit function is $\pi^{u}=v x-c^{u}(x)=v x(q)-c^{u}(x(q))$ and U2's is $\Pi^{u}=V X-C^{u}(X)=V X(Q)-C^{u}(X(Q))$. At stage 1, each Fj determines its own internal transfer price, and at stage 2 both D1 and D2 competes in the final goods market. 


\subsection{Cournot Competition}

At stage 2, D1 chooses $q$ to maximize its profit $\pi^{d}=p(q, Q) q-v x(q)=\pi^{d}(q, Q, v)$, given $v$ and $Q$. The first-order condition is $\pi_{1}^{d}(q, Q, v)=p_{1} q+p-v x_{q}=0$. Similarly, D2 chooses $Q$ to maximize its profit $\Pi^{d}=P(q, Q) Q-V X(Q)=\Pi^{d}(q, Q, V)$, given $V$ and $q$, yielding the first-order condition $\Pi_{2}^{d}(q, Q, V)=P_{2} Q+P-V X_{Q}=0$. The resulting Cournot equilibrium outputs are $q=q(v, V)$ and $Q=Q(v, V)$.

At stage $1, \mathrm{~F} 1$ chooses $v$ to maximize

$$
\begin{aligned}
\hat{\pi}(q, Q, v) & =\pi^{d}(q, Q, v)+\pi^{u}(q, v), \\
\pi(v, V) & \equiv \pi(q(v, V), Q(v, V), v) .
\end{aligned}
$$

The first-order condition is

$$
\pi_{v}(v, V)=\hat{\pi}_{q} q_{v}+\hat{\pi}_{Q} Q_{v}+\hat{\pi}_{v}=\left(v-c_{x}^{u}\right) x_{q} q_{v}+q p_{2} Q_{v}=0
$$

which yields

$$
v-c_{x}^{u}=-\frac{q p_{2} Q_{v}}{x_{q} q_{v}}
$$

By symmetry,

$$
V-C_{X}^{u}=-\frac{q_{V} Q P_{1}}{X_{Q} Q_{V}}
$$

The preceding results show that both firms' transfer prices are not equal to their marginal costs except when the two goods are independent. We have shown in (8) that $q_{v}<0, Q_{V}<0$, sign $q_{V}=-\operatorname{sign} \pi_{12}^{d}$ and sign $Q_{v}=-\operatorname{sign} \Pi_{21}^{d}$. Therefore, we obtain

Proposition 6 Suppose there are two vertically integrated firms that are Cournot-Nash competitors in the final goods market. Then:

(i) Each firm's optimal transfer price is lower than its marginal cost when they are either both ordinary and strategic substitutes or both ordinary and strategic complements.

(ii) Each firm's optimal transfer price is higher than its marginal cost when they are ordinary complements (substitutes) and strategic substitutes (complements). 
To provide an intuitive explanation, it is helpful to look at (36). Imagine initially D2 does not exist. Then the optimal $v$ would have been the marginal $\operatorname{cost} c_{x}^{u}$ as already discussed in Section 2 This can be verified by (36) with $q p_{2} Q_{v}=0$. Now with $\mathrm{D} 2$ as a competitor, the term $q p_{2} Q_{v}$ becomes negative under OSQ and SSQ or under OCQ and SCQ. The condition (36) then requires $\left(v-c_{x}^{u}\right) x_{q} q_{v}>0$. Since $q_{v}$ is negative, $v$ should be lower than the marginal cost. Thus, lowering $v$ is optimal for F1. Similarly, under OCQ and SSQ or under OSQ and SCQ, the opposite result occurs. By the same reasoning, the preceding results apply to F2.

Brander and Spencer (1985) considered a model of horizontal Cournot export rivalry model in which a duopoly competes in a homogeneous good market. They found that under SSQ, the optimal policies for each government are to subsidize its firm's exports. Although our model has a vertical structure, the results show that their governments' subsidy feature is also present in our firm-level policies towards their own downstreams. If a government's export subsidy is interpreted as having the same function as a multinational firm choosing a transfer price lower than its marginal cost, then we have shown the similarity between the horizontal and vertical models; for example, under OSQ and SSQ, our optimal transfer price is below the marginal cost while in the trade model the optimal government's policy is an export subsidy. Schjelderup and Sørgard (1997) examined a model of an MNC that has two operating business units - one is a vertically integrated domestic unit and the other is a downstream division located abroad that competes with a foreign fully integrated firm. They obtained a similar qualitative result on the sign of $v-c_{x}^{u}$.

\subsection{Bertrand competition}

Next, we examine the case of Bertrand competition. By the similar procedure used in Section (3.2), we can derive the two firms' first-order conditions in their choice of $v$ and $V$ :

$$
\begin{array}{r}
\left(v-c_{x}^{u}\right) x_{q} q_{v}^{*}+\left(p-v x_{q}\right) q_{2} P_{v}=0 \\
\left(V-C_{X}^{u}\right) X_{Q} Q_{V}^{*}+\left(P-V X_{Q}\right) p_{V} Q_{1}=0
\end{array}
$$


where $q_{v}^{*}=q_{1} p_{v}+q_{2} P_{v}$ and $Q_{V}^{*}=Q_{2} P_{V}+Q_{1} p_{V}$. Therefore,

$$
\begin{aligned}
v-c_{x}^{u} & =-\frac{\left(p-v x_{q}\right) q_{2} P_{v}}{q_{v}^{*} x_{q}}, \\
V-C_{X}^{u} & =-\frac{\left(P-V X_{Q}\right) p_{V} Q_{1}}{Q_{V}^{*} X_{Q}} .
\end{aligned}
$$

Using the two first-order conditions (17) and (18) with $w$ there now replaced by $V$, we infer that $p_{v}>$ $0, P_{V}>0$, sign $p_{V}=\operatorname{sign} \pi_{12}^{d}$ and sign $P_{v}=\operatorname{sign} \Pi_{21}^{d}$. In addition, we can infer $p-v x_{q}>0$ and $P-V X_{Q}>0$. As a result, if the two goods are OSP (OCP) and SSP (SCP), then both $q_{v}^{*}$ and $Q_{V}^{*}$ are negative so that $v-c_{x}^{u}<0$ and $V-C_{X}^{u}<0$. Note that under OSP (OCP) and SCP (SSP), the signs of $q_{v}^{*}$ and $Q_{V}^{*}$ are ambiguous, but if $q_{v}^{*}$ is assumed to be negative which implies dominant own input price effect on own equilibrium output, then $v-c_{x}^{u}>0$.

Proposition 7 Assume that the two vertically integrated firms are Bertrand competitors in the final goods market. Then:

(i) Each firm's optimal transfer price is lower than its marginal cost if the two goods are either both ordinary and strategic complements or both ordinary and strategic substitutes;

(ii) If the two goods are ordinary complements (substitutes) and strategic substitutes (complements), then each firm's optimal transfer price may be higher or lower than its marginal cost.

(iii) If the two goods are ordinary substitutes (complements) and strategic complements (substitutes), and if there exists dominant own input price effect on own equilibrium output, then each firm's optimal transfer price is higher than its marginal cost.

Similar to the Cournot case, we can now use (39) to provide some intuition. Without D2, the optimal $v$ is $c_{x}^{u}$, But D2's presence creates a change in F1's marginal profit by $\left(p-v x_{q}\right) q_{2} P_{v}$ which is negative under OSP and SSP or under OCP and SCP. Hence, to offset such a reduction, an equivalent positive amount of $\left(v-c_{x}^{u}\right) x_{q} q_{v}^{*}$ must be generated. Again under OSP and SSP or under OCP and SCP, we know $q_{v}^{*}<0$. It follows that the optimal $v$ should be less than $c_{x}^{u}$.

Göx (2000) examined a model similar to ours under the assumption that one unit of output requires one unit of input. He showed that under OSP and SCP, $v-c_{x}^{u}>0 .{ }^{16}$ Schjelderup and Sørgard (1997) also

\footnotetext{
${ }^{16}$ Our equation (39a) under $x_{q}=1$ reduces to $v-c_{x}^{u}=-(p-v) q_{2} P_{v} /\left(q_{1} p_{v}+q_{2} P_{v}\right)$ which can be shown to be equal to Göx's equation (15) $v-c_{x}^{u}=-\left(p-c_{x}^{u}\right) q_{2} P_{v} / q_{1} p_{v}$ under our notation. Note that In the case of $x_{q}=1, p-c_{x}^{u}$ must be positive,
} 
examined a case of Bertrand competition in their model and obtained part of (iii) above. They showed that if the two goods are OSP and SCP and if the MNC's foreign equilibrium output price is negatively related to its foreign equilibrium output, then $v-c_{x}^{u}>0$. Although their model structure is different from ours, their conditions can be shown to be equivalent to ours 17

\subsection{Stackelberg Leader-Follower Competition}

\subsubsection{Stackelberg Quantity Competition}

This section considers D1 as a Stackelberg leader and D2 a follower in quantity competition. As in Section 3.3.1. with $V$ in place of $w$, D2's reaction function now becomes $Q=R(q, V)$ and D1's optimal choice function is $q=q(v, V)$. F1 chooses $v$ and $\mathrm{F} 2$ chooses $V$ to maximize their respective profits. We derive in Appendix 7.3 the following markups:

$$
\begin{aligned}
v-c_{x}^{u} & =0, \\
V-C_{X}^{u} & =-\frac{q_{V} P_{1} Q}{\tilde{Q}_{V}^{*} X_{Q}},
\end{aligned}
$$

where $\tilde{Q}_{V}^{*}=R_{V}+q_{V} R_{q}$. The leader's optimal transfer price is seen to be always U1's marginal cost but the follower's can be higher or lower than U2's marginal cost. By the same method as shown in Section 3.3.1. we find that $R_{V}<0$ and sign $R_{q}=\operatorname{sign} \Pi_{21}^{d}$. Furthermore, $q_{V}=-\pi_{1 V}^{d} / \pi_{11}^{d}$. Thus, the sign of $q_{V}$ is the same as $\pi_{1 V}^{d}$ which is positive (negative) if an increase in $V$ raises (lowers) D1's marginal profit. In order to obtain some definitive results, it is useful to introduce:

Definition 3 An increase in $V$ by $F 2$ raises D1's marginal profit is called vertical strategic complements in quantity (VSCQ), namely, $\pi_{1 V}^{d}>0$. The opposite case is called vertical strategic substitutes in quantity (VSSQ), namely, $\pi_{1 V}^{d}<0.18$

By inspection of the sign patterns in (40b), we obtain

but in the general technology case, $p-c_{x}^{u}$ may not have to be positive. Thus, the condition of dominant own input price effect in (iii) above cannot be dispensed with.

${ }^{17}$ Moorthy (1988) showed that decentralization is preferred to integration under OCP (OSP) and SSP (SCP) since such ordinary and strategic combinations can lower (raise) own (rival's) retail price. Although Moorthy's model is in a different context, we have now seen that such combinations are also important in the determination of optimal transfer prices.

${ }^{18}$ Since a change in $V$ is originated from headquarter of F2, its impact on D1's marginal profit can be regarded as a cross vertical effect. This facilitates the comparison with the horizontal effects SSQ and SCQ. 
Proposition 8 Suppose there are two vertically integrated firms with one being the leader in quantity competition. Then:

(i) The leader firm's optimal transfer price is always its upstream's marginal cost but the follower firm's may be higher or lower than its own upstream marginal cost.

(ii) (a) under strategic substitutes and vertical strategic complements, if the two goods are ordinary complements (substitutes), then the follower's optimal transfer price is higher (lower) than its marginal cost; (b) under strategic complements and vertical strategic substitutes, if the two goods are ordinary substitutes (complements), the same result follows.

Since D1 is the quantity leader, it can effectively control the downstream market. F1 therefore can treat the whole organization as an integrated entity so that $v$ is set at $c_{x}^{u}$. Brander and Spencer (1985) found that if the home firm is a Stackelberg leader in quantity in a "horizontal" export rivalry model, its government's optimal policy is non-intervention free trade. In our vertical model, however, F1 must play an active role by setting $v=c_{x}^{u}$ for $\mathrm{D} 1$.

For F2, its optimal choice of $V$ can be intuitively explained by (44). For example, under VSC, OSQ and $\mathrm{SSQ}$, the second term in 44$), q_{V} Q P_{1}$, is negative. It thus calls for a positive $X_{Q} \tilde{Q}_{V}^{*}\left(V-C_{X}^{u}\right)$ to satisfy 44. Since $\tilde{Q}_{V}^{*}<0$ under VSC and SSQ, we conclude $V<C_{X}^{u}$. Other cases can be similarly analyzed.

\subsubsection{Stackelberg Price Competition}

Lastly, we consider the case of Stackelberg price competition. By the similar procedure used in Section 3.3.2, we obtain in Appendix 7.4 the following results:

$$
\begin{aligned}
\left(v-c_{x}^{u}\right) x_{q} \tilde{q}_{p}^{*} p_{v} & =0 \\
V-C_{X}^{u} & =-\frac{\left(P-V X_{Q}\right) p_{V} Q_{1}}{X_{Q}\left(p_{V} Q_{1}+Q_{2} \tilde{P}_{V}^{*}\right)}
\end{aligned}
$$

where $\tilde{P}_{V}^{*}=p_{V} \tilde{R}_{p}+\tilde{R}_{V}$, and $\tilde{q}_{p}^{*}=q_{1}+q_{2} \tilde{R}_{p}$ which is already defined in $33 \mathrm{~b}, 19$ Therefore, the leader's optimal transfer price is its marginal cost as long as $\tilde{q}_{p}^{*} p_{v} \neq 0$; namely, a change in $v$ through the induced changes in $p$ always changes the equilibrium $q$. For the follower, however, its optimal transfer price may

\footnotetext{
${ }^{19}$ As a reminder, $p_{V}$ here is defined on the function $p(v, V)$. One might be tempted to think of the counterpart of $\tilde{P}_{V}^{*}$, which would have been $\tilde{p}_{V}^{*}$. But this counterpart does not exist.
} 
be higher or lower than its marginal cost. From the first-order conditions of D1 and D2, we have $p_{v}>0$, $\tilde{R}_{V}>0$ and $p_{V}=-\pi_{1 V}^{d} / \pi_{11}^{d}$. The sign of $p_{V}$ is thus the same as $\pi_{1 V}^{d}$.

The counterparts of VSCQ and VSSQ are

Definition 4 An increase in F2's $V$ raises D1's marginal profitability of p is called vertical strategic complements in price (VSCP), namely, $\pi_{1 V}^{d}>0$. The opposite case is called vertical strategic substitutes in price (VSSP), namely, $\pi_{1 V}^{d}<0$.

From D2's first-order condition, we know $P-V X_{Q}$ is always positive. Furthermore, $\tilde{R}_{p}=-\Pi_{21}^{d} / \Pi_{22}^{d} \gtreqless$ 0 if and only if $\Pi_{21}^{d} \gtreqless 0$. By checking the sign patterns in $41 \mathrm{~b}$, we obtain

Proposition 9 Suppose there are two vertically integrated firms engaging in Stackelberg price competition in the final goods market. Then:

(i) The leader's optimal transfer price is its marginal cost as long as a change in $v$ through induced changes in p changes the equilibrium q; the follower's optimal transfer price may be higher or lower than its marginal cost.

(ii) (a) Under vertical strategic complements in price, if the two goods are ordinary and strategic complements, then the follower's optimal transfer price is lower than its marginal cost; (b) under vertical strategic substitutes in price, if they are ordinary and strategic substitutes, then the follower's optimal transfer price is also lower than its marginal cost.

Since D1 controls the downstream market, again F1 can use marginal cost pricing as in the integrated case. By the same method as in Section 4.3.1, we can use (45) to provide intuitive explanations of other results.

\section{Optimal Transfer Pricing in the present of Income and Trade taxes}

With our general structures examined, it is straightforward to introduce corporate income tax and import tariff. To illustrate, consider the model in Section 4.1. Assume D1 is located in a foreign country. Let $t$ and $T$ be the home and foreign ad valorem income tax rates and $\Gamma$ be the foreign ad valorem import tariff rate. D1 is assumed to maximize $\pi^{d}=(p(q, Q) q-v(1+\Gamma) x(q))$ since foreign income tax payment is assumed to be handled by F1. F1 maximizes after-tax total profits $\pi=(1-t) \pi^{u}+(1-T) \pi^{d}$. Here $\Pi^{d}$ is 
F2's profit itself so it maximizes the after-tax profit $\Pi^{d}=(1-T)[P(q, Q) Q-V X(Q)]$. It can be shown that the resulting optimal markup for F1 is

$$
v-c_{x}^{u}=\frac{(1-T)}{(1-t)}\left[\frac{\Gamma-\kappa}{x_{q} q_{v}} x-\frac{q p_{2} Q_{v}}{x_{q} q_{v}}\right]
$$

where $\kappa=(T-t) /(1-T)$. Furthermore, $V-C_{X}^{u}$ has the same form as the one in (38). Comparing (37) and (42), we see that Proposition 6 can now be restated as

Proposition 10 Suppose there are two vertically integrated firms that are Cournot-Nash competitors in the foreign final goods market. Then:

(i) Each firm's optimal transfer price is lower than its marginal cost when they are either both ordinary and strategic substitutes or both ordinary and strategic complements and when $\kappa<\Gamma$.

(ii) Each firm's optimal transfer price is higher than its marginal cost when they are ordinary complements (substitutes) and strategic substitutes (complements) and when $\kappa>\Gamma$.

By similar method, it is easy to introduce taxes and tariff into all models examined in this paper. Again as illustrated in the preceding proposition, $\kappa$ and $\Gamma$ become additional important factors in determining the optimal transfer pricing policy 20

\section{Concluding Remarks}

In this paper, we have examined three minimalist vertical models with a focus on the factors that affect an MNC's optimal transfer pricing policy. We have shown that the optimal policy depends crucially on the vertical structure, the production technology, the demand characteristics and the competition mode. We found that in the model of a vertically integrated intermediate input monopoly competing against a foreign downstream firm, the integrated firm tends to discriminate against its rival and favor its own downstream in its pricing policy; in addition, in the Stackelberg quantity and price competition, the optimal transfer price may be higher or lower than the marginal cost, though in the model with two vertically integrated firms, the leader's optimal transfer price is always equal to its marginal cost. To facilitate the analysis, we introduced in Stackelberg competition the concepts of vertical strategic substitutes and complements to determine the

\footnotetext{
${ }^{20}$ Schjelderup and Sørgard (1997) already derived (i) above (see their Proposition 2).
} 
follower firm's transfer pricing policy. Again we showed that the combinations of vertical and horizontal strategic elements together with ordinary substitutes or complements can yield diverse patterns of follower's optimal transfer pricing.

It is the received consensus that the degree of competition is higher in price than in quantity. For example, in the trade literature of export rivalry models, when firms are Bertrand competitors, the optimal policies for governments are likely to impose export taxes to discourage excessive competition between firms; however, in the Cournot case, the optimal policies are likely to encourage more competition with export subsidies ${ }^{21}$ Such results are derived from the horizontal models. In our vertical models both firms can play a similar role like governments in promoting or reducing the degree of downstream competition, even though the objective functions of the policy makers between these two types of models are very different. Note that in the export-rivalry models where there is no consumer surplus to consider, the results in our model of two vertically integrated firms can be directly applied.

Having delineated the various crucial factors in determining the optimal transfer pricing policy, this paper has laid a foundation for further studies in transfer pricing problem in more general structures. We have also illustrated how the optimal transfer pricing is affected by income tax and tariff distortions in our general models. When all these factors are considered, there are clear cases in which the optimal transfer pricing policy may not be determined by simply following the common practice of shifting profits from high- to low-tax jurisdictions.

\section{Appendix}

\subsection{Derivation of the Results in Section 3.2}

From 21, the first-order conditions are $\pi_{v}(v, w)=\pi_{v}^{u}+\pi_{v}^{d}=0, \pi_{w}(v, w)=\pi_{w}^{u}+\pi_{w}^{d}=0$. Using (16) and 20a), we obtain

$$
\begin{aligned}
& \pi_{v}(v, w)=\hat{\pi}_{1}(p, P, v, w) p_{v}+\hat{\pi}_{2}(p, P, v, w) P_{v}+\hat{\pi}_{v}(p, P, v, w)=0 \\
& \pi_{w}(v, w)=\hat{\pi}_{1}(p, P, v, w) p_{w}+\hat{\pi}_{2}(p, P, v, w) P_{w}+\hat{\pi}_{w}(p, P, v, w)=0
\end{aligned}
$$

\footnotetext{
${ }^{21}$ See for example, Brander and Spencer (1985) and Eaton and Grossman (1986).
} 
where

$$
\begin{aligned}
& \hat{\pi}_{1}=\hat{\pi}_{1}^{d}+\hat{\pi}_{1}^{u}=\hat{\pi}_{1}^{u}=\left(v-c_{x}^{u}\right) x_{q} q_{1}+\left(w-c_{X}^{u}\right) X_{Q} Q_{1}, \\
& \hat{\pi}_{2}=\hat{\pi}_{2}^{d}+\hat{\pi}_{2}^{u}=p q_{2}-v x_{q} q_{2}+\left(v-c_{x}^{u}\right) x_{q} q_{2}+\left(w-c_{x}^{u}\right) X_{Q} Q_{2}, \\
& \hat{\pi}_{v}=-x+x=0, \hat{\pi}_{w}=X
\end{aligned}
$$

by the first-order condition $\hat{\pi}_{1}^{d}=0$. Therefore, the two equations in (43) become

$$
\begin{gathered}
\left(q_{1} p_{v}+q_{2} P_{v}\right)\left(v-c_{x}\right) x_{q}+\left(Q_{1} p_{v}+Q_{2} P_{v}\right)\left(w-c_{X}\right) X_{Q}=-\left(p q_{2}-v x_{q} q_{2}\right) P_{v}, \\
\left(q_{1} p_{w}+q_{2} P_{w}\right)\left(v-c_{x}\right) x_{q}+\left(Q_{1} p_{w}+Q_{2} P_{w}\right)\left(w-c_{X}\right) X_{Q}=-\left(p q_{2}-v x_{q} q_{2}\right) P_{w}-X,
\end{gathered}
$$

which can be solved for (22).

\subsection{Derivation of the Results in Section 3.3.2}

From (32), the first-order conditions are:

$$
\begin{aligned}
& \pi_{v}(v, w)=\pi_{v}^{u}(v, w)+\pi_{v}^{d}(v, w)=0 \\
& \pi_{w}(v, w)=\pi_{w}^{u}(v, w)+\pi_{w}^{d}(v, w)=0
\end{aligned}
$$

where 22

$$
\begin{aligned}
& \pi_{v}^{u}(v, w)=x+\left(v-c_{x}^{u}\right) x_{q} \tilde{q}_{p}^{*} p_{v}+\left(w-c_{X}^{u}\right) X_{Q} \tilde{Q}_{p}^{*} p_{v}, \pi_{v}^{d}(v, w)=-x, \\
& \pi_{w}^{u}(v, w)=\left(v-c_{x}^{u}\right) x_{q}\left(\tilde{q}_{p}^{*} p_{w}+q_{2} \tilde{R}_{w}\right)+\left(w-c_{X}^{u}\right) X_{Q}\left(\tilde{Q}_{p}^{*} p_{w}+Q_{2} \tilde{R}_{w}\right)+X, \\
& \pi_{w}^{d}(v, w)=\left(p-v x_{q}\right) q_{2} \tilde{R}_{w},
\end{aligned}
$$

$\tilde{q}_{p}^{*}=q_{1}+q_{2} \tilde{R}_{p}$ and $\tilde{Q}_{p}^{*}=Q_{1}+Q_{2} \tilde{R}_{p}$. It follows that

$$
\begin{aligned}
\left(v-c_{x}^{u}\right) x_{q} \tilde{q}_{p}^{*} p_{v}+\left(w-c_{X}^{u}\right) X_{Q} \tilde{Q}_{p}^{*} p_{v} & =0 \\
\left(v-c_{x}^{u}\right) x_{q}\left(\tilde{q}_{p}^{*} p_{w}+q_{2} \tilde{R}_{w}\right)+\left(w-c_{X}^{u}\right) X_{Q}\left(\tilde{Q}_{p}^{*} p_{w}+Q_{2} \tilde{R}_{w}\right) & =-X-\left(p-v x_{q}\right) q_{2} \tilde{R}_{w}
\end{aligned}
$$

\footnotetext{
${ }^{22}$ In deriving the result $\pi_{v}^{d}(v, w)=-x, \mathrm{D} 1$ 's first-order condition for profit maximization has been used.
} 
which can be solved for (33).

\subsection{Derivation of the Results in Section 4.3.1}

For F1, let

$$
\begin{aligned}
& \hat{\pi}^{d}(q, v)=p(q, R(q, V)) q-v x(q), \pi^{d}(v, V)=\hat{\pi}^{d}(q(v, V), v), \\
& \hat{\pi}^{u}(q, v)=v x(q)-c^{u}(x(q)), \pi^{u}(v, V)=\hat{\pi}^{u}(q(v, V), v), \\
& \pi(v, V)=\pi^{d}(v, V)+\pi^{u}(v, V) .
\end{aligned}
$$

We have $\pi_{v}^{d}(v, V)=\hat{\pi}_{1}^{d} q_{v}+\hat{\pi}_{v}^{d}=\hat{\pi}_{v}^{d}=-x$ since $\hat{\pi}_{1}^{d}=0$ by D1's first-order condition. Also, $\pi_{v}^{u}(v, V)=$ $x+\left(v-c_{x}^{u}\right) x_{q} q_{v}$. Thus, $\pi_{v}=\left(v-c_{x}^{u}\right) x_{q} q_{v}=0$, which leads to 40a since $x_{q}>0$ and $q_{v}<0$.

For F2, let

$$
\begin{aligned}
\hat{\Pi}^{d}(q, V) & =P(q, R(q, V)) R(q, V)-V X(R(q, V)), \\
\Pi^{d}(v, V) & =\hat{\Pi}^{d}(q(v, V), V), \\
\hat{\Pi}^{u}(q, V) & =V X(R(q, V))-C^{u}(X(R(q, V))), \\
\Pi^{u}(v, V) & =\hat{\Pi}^{u}(q(v, V), V), \\
\Pi(q, V) & =\hat{\Pi}^{d}(q, V)+\hat{\Pi}^{u}(q, V) .
\end{aligned}
$$

Then, $\Pi_{V}^{d}(v, V)=q_{V} Q P_{1}+\left(Q P_{2}+P-V X_{Q}\right)\left(q_{V} R_{q}+R_{V}\right)-X=q_{V} Q P_{1}-X$ since $Q P_{2}+P-$ $V X_{Q}=0$ by D2's first-order condition. In addition, $\Pi_{V}^{u}(v, V)=X+X_{Q} \tilde{Q}_{V}^{*}\left(V-C_{X}^{u}\right)$ where $\tilde{Q}_{V}^{*}=$ $\left(q_{V} R_{q}+R_{V}\right)$. Therefore,

$$
\Pi_{V}(v, V)=X_{Q} \tilde{Q}_{V}^{*}\left(V-C_{X}^{u}\right)+q_{V} Q P_{1}=0,
$$

which is then solved for 40b. 


\subsection{Derivation of the Results in Section 4.3 .2}

For F1, let

$$
\begin{aligned}
& \hat{\pi}^{d}(p, v)=p q(p, \tilde{R}(p, V))-v x(q(p, \tilde{R}(p, V))), \pi^{d}(v, V)=\hat{\pi}^{d}(p(v, V), v), \\
& \hat{\pi}^{u}(p, v)=v x(q(p, \tilde{R}(p, V)))-c^{u}\left(x(q(p, \tilde{R}(p, V))), \pi^{u}(v, V)=\hat{\pi}^{u}(p(v, V), v),\right. \\
& \pi(v, V)=\pi^{d}(v, V)+\pi^{u}(v, V) .
\end{aligned}
$$

We have $\pi_{v}^{d}(v, V)=\hat{\pi}_{1}^{d} p_{v}+\hat{\pi}_{v}^{d}=\hat{\pi}_{v}^{d}=-x$ since $\hat{\pi}_{1}^{d}=0$ by D1's first-order condition. Also, $\pi_{v}^{u}(v, V)=$ $x+\left(v-c_{x}^{u}\right) x_{q} \tilde{q}_{v}^{*}$ where $\tilde{q}_{v}^{*}=\left(q_{1}+q_{2} \tilde{R}_{p}\right) p_{v}$. Thus, $\pi_{v}=\left(v-c_{x}^{u}\right) x_{q} \tilde{q}_{v}^{*}=0$, which leads to 41a.

For F2, let

$$
\begin{aligned}
\hat{\Pi}^{d}(p, V) & =\tilde{R}(p, V) Q(p, \tilde{R}(p, V))-V X(Q(p, \tilde{R}(p, V))), \Pi^{d}(v, V)=\hat{\Pi}^{d}(p(v, V), V), \\
\hat{\Pi}^{u}(p, V) & =V X(Q(p, \tilde{R}(p, V)))-C^{u}(X(Q(p, \tilde{R}(p, V)))), \Pi^{u}(v, V)=\hat{\Pi}^{u}(p(v, V), V), \\
\Pi(v, V) & =\Pi^{d}(v, V)+\Pi^{u}(v, V) .
\end{aligned}
$$

Using D2's first-order condition $Q+P Q_{2}-V X_{Q} Q_{2}=0$, we obtain

$$
\begin{aligned}
& \hat{\Pi}_{1}^{d}=\left(P-V X_{Q}\right) Q_{1}+\left(P Q_{2}+Q-V X_{Q} Q_{2}\right) \tilde{R}_{p}=\left(P-V X_{Q}\right) Q_{1}, \\
& \hat{\Pi}_{V}^{d}=\left(P Q_{2}+Q-V X_{Q} Q_{2}\right) \tilde{R}_{V}-X=-X
\end{aligned}
$$

In addition, $\Pi_{V}^{d}=\left(P-V X_{Q}\right) p_{V} Q_{1}-X$ and $\Pi_{V}^{u}(v, V)=X+\left(V-C_{X}^{u}\right) X_{Q}\left(p_{V} Q_{1}+Q_{2} \tilde{P}_{V}^{*}\right)$ where $\tilde{P}_{V}^{*}=p_{V} \tilde{R}_{p}+\tilde{R}_{V}$. It follows that

$$
\Pi_{V}=\left(P-V X_{Q}\right) p_{V} Q_{1}+\left(V-C_{X}^{u}\right) X_{Q}\left(p_{V} Q_{1}+Q_{2} \tilde{P}_{V}^{*}\right)=0
$$

which can be solved for 41b. 


\section{References}

Blair, Roger D., David L. Kaserman and Richard E. Romano (1989), "A pedagogical treatment of bilateral monopoly," Southern Economic Journal 55(4), 831-841.

Bonanno, Giacomo and John Vickers (1988), "Vertical separation," Journal of Industrial Economics 36(3), $257-265$.

Bond, Eric (1980), "Optimal transfer pricing when tax rates differ," Southern Economic Journal 47(1), $191-200$

Brander, James A. and Barbara. J. Spencer (1985), "Export subsidies and international market share rivalry," Journal of International Economics 18, 83-100.

Bulow, Jeremy, John Geanakoplos and Paul Klemperer (1985), "Multimarket oligopoly: strategic substitutes and complements," Journal of Political Economy 93(3), 488-511.

Chang, Winston W. and Hajime Sugeta (2004), "Conjectural variations, market power, and optimal trade policy in a vertically related industry," Review of International Economics 12(1), 12-26.

Copithorne, L. W. (1971), "International corporate transfer prices and government policy," Canadian Journal of Economics 4(3), 324-341.

Diewert, Erwin (1985), "Transfer pricing and economic efficiency," in: A. M. Rugman and L. Eden, eds., Multinationals and Transfer Pricing (Croom Helm Ltd.), 47-81.

Dowrick, Steve (1986), "von Stackelberg and Cournot duopoly: choosing roles," The RAND Journal of Economics 17(2), 251-260.

Eaton, Jonathan and Gene Grossman (1986), "Optimal trade and industrial policy under oligopoly," Quarterly Journal of Economics 101(2), 383-406.

Eden, Lorraine (1978), "Vertically integrated multinationals: A microeconomic analysis," Canadian Journal of Economics 11(3), 534-546.

Eden, Lorraine (1983), "Transfer pricing policies under tariff barriers," Canadian Journal of Economics $16(4), 669-685$. 
Eden, Lorraine (1985), "The microeconomics of transfer pricing," in: A. M. Rugman and L. Eden, eds., Multinationals and Transfer Pricing (Croom Helm Ltd.), 13-46.

Göx, Robert F. (2000), "Strategic transfer pricing, absorption costing, and observability," Management Accounting Research 11, 327-348.

Göx, Robert F. and Ulf Schiller (2006), "An economic perspective on transfer pricing," Handbooks of Management Accounting Research (2), 673-695.

Hines, Jr., James (1990), "The transfer pricing problem: where the profits are," NBER Working paper No. 3538.

Hirshleifer, Jack (1956), "On the economics of transfer pricing," Journal of Business 29(3), 172-184.

Horst, Thomas (1971), "The theory of the multinational firm: optimal behavior under different tariff and tax rates," Journal of Political Economy 79(5), 1059-1072.

Horst, Thomas (1972), "The industrial composition of U.S. exports and subsidiary sales to the Canadian market," American Economic Review 62(1/2), 37-45.

Moorthy, K. Sridhar (1988), "Strategic decentralization in channels," Marketing Science 7(4), 335-355.

Nielsen, Søren Bo, Pascalis Raimondos-Moller and Guttorm Schjelderup (2008), "Taxes and Decision Rights in Multinationals," Journal of Public Economic Theory 10(2), 245-258.

Schjelderup, Guttorm and Lars Sørgard (1997), "Transfer pricing as a strategic device for decentralized multinationals," International Tax and Public Finance 4, 277-290.

Vernon, John and Daniel Graham (1971), "Profitability of monopolization by vertical integration," Journal of Political Economy 79(4), 924-925.

Vickers, John (1985), "Delegation and the theory of the firm," Economic Journal 95(380a), 138-147.

Zhao, Laixun (2000), "Decentralization and transfer pricing under oligopoly," Southern Economic Journal 67(2), 414-426. 